\title{
Market Share and Cooperation of Telecom Operators and Agents based on Channel Conflicts
}

\author{
Xingyou Zheng \\ Glorious Sun School of Business and Management \\ Donghua University \\ Shanghai, China \\ zhengxingyou@shtel.com.cn
}

\begin{abstract}
As to the internal behavior of the telecommunications industry, channel conflicts play an critical impact on the entire supply chain system. The channel conflicts in telecommunications industry source from profit motive between operators and agents, as well as competitive market pressures. In this paper, on the basis of profit function of telecom operators and agents, through the solving of the profit curve model and determining preferences interval, so as to obtain the best cooperation proportion of the market share of telecom operators and agents which will provide a theoretical support for avoidance of channel conflict and achieve mutual benefit and win-win of the telecom operators and agents.
\end{abstract}

Keywords- channel conflicts; operators; agent; market share.

\section{INTRODUCTION}

With the development of economy, telecommunications industry has been developing at a high speed. Especially in recent years, accompanied by separation of enterprise from government, corporate restructuring as well as $3 \mathrm{G}$ licenses issue reform, The three operators Mobile, Telecom and Unicom have accelerated to offer full-service, which has made telecommunications industry an increasingly competitive market. The carriers are facing increasing challenges due to the growing homogenization of the products and services provided by telecom operators, the theme of the competition gradually has transited from priceled to marketing network. Industry competition has developed to channel resources competition from network coverage scale, number of customers, and type of business as well as operation mode. Channel has become an essential in the development of the telecommunications industry, an important resource and means of competition, an important channel linking telecommunications businesses and their customers, with the expansion of the market and the role of feedback information, also affecting corporate strategy and business objectives.

As for telecommunications industry, operators, distributors and consumers comprise a typical circulation system; the behavior of the agents in the middle position affects the strength of competition of the carrier market. Therefore, quickly established a reasonable layout, quick response, competitive, loyal marketing channel system, will be the key to the operators to effectively resist the changes in the market environment [1]. In order to take advantage of channel, operators undoubtedly need to focus on the channels, only stimulate the enthusiasm of the agents entire channel efficiency can be effectively enhanced [2].

At the same time, due to the different interests, conflict of telecom operators and agents becomes more prominent. In some places, some agents hoarding and distributing the package card resources leading to market chaos has caused a series of channel conflicts such as shortage of resources, customer complaints [3]. As for large chain retailers with considerable power such as Suning, Gome and D.phone, carriers in the past to treat the fragmented social channels (or non-owned channels) is no longer applicable, and agents in games being gradually occupy a certain position. How to control and manage the agents so that their actions are consistent with the overall interests of the telecom operators has become an important issue that cannot be avoided by the operators. Learning from the research, this article determined the market share of the telecom operators and agents in order to coordinate the relationship between operators and agents, maximum ease of telecommunications industry channel conflict, to ensure the efficient operation and get a win-win situation.

\section{RELATED CONCEPTS OF CHANNEL CONFLICTS}

"Channels" comes from the English word. The channel mentioned in this paper is referred to "Marketing Channel" or "Distribution Channel”. In a buyer's market environment, as carrier of a product or service, channel connects operators with customers and directly linked to operators' image. In most cases, due to the limitation of time, geographical conditions, consumers cannot make a purchase directly from manufacturers [4]. Task of channel is to send appropriate product to the appropriate locations at the appropriate time, to facilitate the purchase of the consumer. Therefore, the marketing channels are interdependent organizations to promote products or services successfully being used or consumed. In order to sell their products to the end user, it is necessary to sell them to users or intermediaries that constitute marketing channels [5].

Channel conflict is usually referred that one member in channel see another channel member as competitor who prevent and hinder his goals. Channel conflict is kind of a hostile or discordant status among customers and dynamic process from potential conflict state to significant conflict state [6]. When channel member' behavior is contrary to the behavior of members in other channel, channel conflict arises. Conflicts center on opponent and its goal is also 
controlled by the channel partners. Channel conflict includes the following states: channel member is aware that the other channel member is preventing him achieve their goals or effective operation. Or channel members are aware that another channel member is engaged in activities that threaten its interests to obtain the scarcity of resources [7]. In the e-commerce environment, manufacturers open online channel and make them suppliers of traditional retailers as well as direct competitors, which will be boycotted by channel partners such as retailers, distributors and dealers, which leads to the vicious competition in the marketing channels. It is pointed out that internet technology has many negative effects of the industrial structure: Internet technology tends to weaken the bargaining power of the buyer (retailer), bring down new competitors barrier of entering and create new alternatives or services, intensify competition between competitors and encourage destructive price competition [8].

There are many reasons causing channel conflicts, which can mainly be attributed to inconsistence of the target of the members, undefined tasks and rights, different feeling and high dependency [9]. Channel conflict arises from conflict of interests of members and changes in market environment will ask for new change of the existing channels, which cause channel conflict such as generation of new ways of distribution and unbalanced regional economic development. Through research of game theory, it is found that there are two essential reasons that lead to channel conflicts: One is individual rational behavior, the other one is difference of the target in the channel between individuals, while horizontal and vertical channel conflict is due to the different quality of channel distributors [10].

One solution to this kind of conflict is setting the same price no matter traditional retail channel or online channel not including delivery cost, so online sales price will be higher than traditional retail price. More scholars, however, have explored the problem of cooperation of channel members based on methods of game theory and information economics. Mixed game model has been built based on assumption that manufacturers and distributors will collaborate according to certain trading conditions [11]. They think that tacit collaboration of manufacturers and distributors in the distribution channel management is an effective means to adapt to market changes and improve channel competitiveness.

Channel conflict in telecom is generated by dispute of interests, telecom operators don not allow their own store representatives to do business for other telecom operators. However, no one can prevent agents from gaining market share and keeping competitive advantage. Basically, channel conflict in telecommunications industry is limited specifically to conflict occurred in the longitudinal channel, which is between carriers and agents in different levels of channel, rather than conflict occurred in horizontal channel relationships. Vertical channel conflict is important for telecom operators and agents, these conflicts are not only frequent occurrence, and through the mediation of the conflict are better able to meet consumer demand, to improve the strength of competition in the telecommunications enterprises [12]. Meanwhile, good longitudinal relationship is one precondition for smooth and effective running of channels, which depends on behaviors of operators and agents.

\section{PROFIT FUNCTION OF TELECOM OPERATORS AND AGENTS}

Channel conflicts in telecommunications industry comes from both the profit motive between carriers and agents, and strong competitive market pressures forced. Assume that the business of the telecommunications market demand function is linear relationship: $Q=a-b P_{2}(a \succ 0, b \succ 0$ constants), in which $Q$ refers to sales of telecommunications business; $P_{2}$ is the agent's decision variable representing the price that agents sell telecom business to consumer.

The profits of the telecom operator can be expressed as:

$$
\pi_{1}=\lambda\left(P_{2}-P_{1}-C_{2}\right) Q+\left(P_{1}-C_{1}\right) Q
$$

The profits of the telecom agent can be expressed as:

$$
\pi_{2}=(1-\lambda)\left(P_{2}-P_{1}-C_{2}\right) Q
$$

In which, $\lambda(\lambda \in[0,1])$ represents the profit sharing ratio operator get from agents profit on sales; $(1-\lambda)$ refers to the rest of profit. $P_{1}$ is decision variable of operator representing the whole price that operator sell telecom business to agents; $C_{1} 、 C_{2}$ denote cost of operators' business and cost of sales respectively.

In (1)and(2), $\lambda$ is direct factor which is market share of operators and agents. In the extreme case of noncooperation between the two sides, if $\lambda=0$, profit sharing ratio for telecom operators is 0 , and agents monopolize the whole profit. The profit of operators: $\pi_{1}=\left(P_{1}-C_{1}\right) Q$; The profit of agents: $\pi_{2}=\left(P_{2}-P_{1}-C_{2}\right) Q$. If $\lambda=1$, operators will monopolize the whole profit, then $\pi_{1}=\left(P_{2}-C_{2}-C_{1}\right) Q$; Agents will withdraw from the market. Since profit is 0 , the unit cost of sales of telecommunications business $C_{2}$ has transferred to the operator's own cost of sales.

In market transactions, when agents enable to maximize profits, $\partial \pi_{2} / \partial P_{2}=0$ should be satisfied. We can get:

$$
\begin{gathered}
\partial\left[(1-\lambda)\left(P_{2}-P_{1}-C_{2}\right) Q\right] / \partial P_{2}=0, Q=a-b P_{2} . \\
P_{2}=\frac{a+b\left(P_{1}+C_{2}\right)}{2 b}
\end{gathered}
$$

When agents enable to maximize profits, $\partial \pi_{1} / \partial P_{1}=0$ $\partial\left[\lambda\left(P_{2}-P_{1}-C_{2}\right) Q+\left(P_{1}-C_{1}\right) Q\right] / \partial P_{1}=0$ are to be satisfied.

$$
P_{1}=\frac{(1-\lambda) a+b\left[C_{1}-(1-\lambda) C_{2}\right]}{(2-\lambda) b}
$$




$$
P_{2}=\frac{(3-2 \lambda) a+b\left(C_{1}+C_{2}\right)}{2(2-\lambda) b}
$$

Based on the formulas mentioned above, telecom operators and agents profit function can be expressed as:

$$
\begin{aligned}
& \pi_{1}=\frac{\left[a-b\left(C_{1}+C_{2}\right)\right]^{2}}{4 b(2-\lambda)} \\
& \pi_{2}=\frac{(1-\lambda)\left[a-b\left(C_{1}+C_{2}\right)\right]^{2}}{4 b(2-\lambda)^{2}}
\end{aligned}
$$

\section{THE COOPERATIVE PREFERENCES INTERVAL BETWEEN OPERATORS AND AGENTS}

Marketing channel system of the telecommunications industry is influenced by market policies, structures. Form of make channel members different targets. Telecom operators

channel, different level is tending to cause conflicts. Each channel member pursues to maximize personal interests which often want to downstream agents not only sell their own products, but also need to provide a series of sales and service to meet their own business requirements, meanwhile the agents complained that operators are not new demand for additional input and providing appropriate training.

Profit function of telecom operators and agents assumes that all telecom services are purchased from agents at price $P_{2}$, and cooperative relationship between operators and agents can be identified by $\lambda$. In order to describe the curve that the profits of operators and agents change with profit sharing ratio, set $\frac{\left[a-b\left(C_{1}+C_{2}\right)\right]^{2}}{4 b}=R$ (constant). Function values are calculated in Table1 according to formula (6) and (7).

TABLE I. TELECOM OPERATORS AND AGENTS FUNCTION VALUE CHANGES

\begin{tabular}{c|c|c|c|c|c}
\hline & Function & $\lambda=0$ & $\lambda=1$ & First derivative & Second derivative \\
\hline $\begin{array}{c}\text { Profit of } \\
\text { operator }\end{array}$ & $\pi_{1}=\frac{R}{(2-\lambda)}$ & $\pi_{1}^{0}=\frac{R}{2}$ & $\pi_{1}^{1}=R$ & $\frac{R}{(2-\lambda)^{2}}$ & $\frac{2 R}{(2-\lambda)^{3}}$ \\
\hline $\begin{array}{c}\text { Profit of } \\
\text { agent }\end{array}$ & $\pi_{2}=\frac{(1-\lambda) R}{(2-\lambda)^{2}}$ & $\pi_{2}^{0}=\frac{R}{4}$ & $\pi_{2}^{1}=0$ & $-\frac{\lambda R}{(2-\lambda)^{3}}$ & $-\frac{2(1+\lambda) R}{(2-\lambda)^{4}}$ \\
\hline
\end{tabular}

According to the data in the above table, $\frac{R}{4}$ is taken as the vertical unit and the changes in market share of telecom operators and agents are showed in Table1.

As it can be seen from Figure 1, profit of telecom operators is increasing with sharing ratio and increase rate close to the area 1 is higher than that close to the area 0 . In operators profit curves, we can find an critical preference point $\lambda_{1}^{*}$ where rate of increase before the point is lower than average while rate of increase after the point is higher than average.For the same incremental profit distribution (the market share increment), there are significant differences of incremental profits in different regions, so operators would expect the profit sharing ratio the higher the better. But in reality, telecom operators can not completely occupy the channel profit but choose to cooperate with agents in a range where there is a significant increase in its profits. As for telecom operators, preference interval is where profit increase rate is higher than the average $\left(\left[\lambda_{1}^{*}, 1\right]\right)$.

The telecom agents profit curve in Figure 1 showed a decreasing trend, its profit is descending with the inceraseing in operators' profit sharing ratio and decrease rate close to the area 1 is higher than that close to the area 0 . Similarly, in agents profit curves, we can find an critical

preference point $\lambda_{2}^{*}$ where the rate of decrease equals to the average. But in reality, telecom operators occupy a certain amount of the channel profit, so agents have to cooperate with operators in a range where there is a significant increase in its profits. As for telecom agents, preference interval is where operators sharing ratio increases while the profit decreased rate not significantly $\left(\left[0, \lambda_{2}^{*}\right]\right)$. 


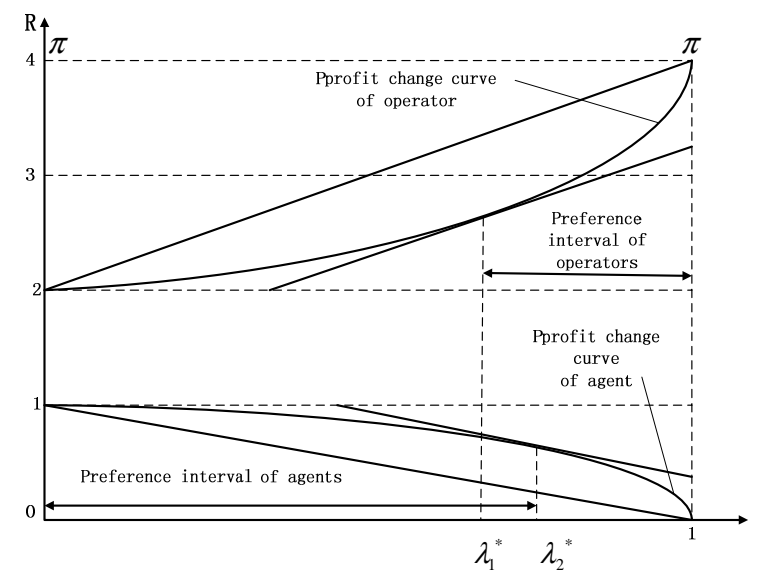

Figure 1. Changes in market share of telecom operators and agents

\section{RESEARCH OF MARKET SHARE OF THE TELECOM OPERATORS AND AGENTS}

In the telecommunications market transactions, operators can take obvious advantage of economic strength and operational capability and try to expand proportion of its own channels and enhance controlling force. China's three telecom operators are planning to open proprietary channels like flagship stores, brand stores to enhance their competitiveness in the market and controlling force. With the growing strength of the various telecom operators, owning channel is the main trend. For example, China mobile collaborates with terminal manufacturers and establishes Dingxun terminal sales company. Through customizing net book, China Telecom established Tianyi terminal company and continued to expand control over the marketing channels. However, many businesses in the telecommunications market are realized through social channels and a close relationship is formed between telecom operators and agents. Operators and agents are rational economic man; there is a pursuit of maximizing their own interests and rights. No matter competition or cooperation, are interests-oriented results. Agents don not responsibilities and obligations to sacrifice their own interests for the operators' goals, but sometimes they will make use of market information resources and defects of market strategy of operators to falsify goods, promote at a low price.

The pursuit of short-term interest of telecom agents does not mean rejecting the long-term interests, but lead to behavior channel conflicts in telecommunications industry. Due to the intensification of market competition, horizontal conflict between dealers and distributors in the channels often happens. The serious consequences of channel conflict will cause the market price system confusion and affect enterprise image. Therefore, in the process of establishing marketing channels. Reasonable determining the market share of the telecom operators and agents, preventing the conflicts in a timely manner and the occurrence of the competition, and maintaining stable and healthy development of the channels become important task of marketing management of telecom operators.
According to Lagrange Mean Value Theorem, for telecom operators, the first derivative of profit function:

$\frac{\partial \pi_{1}}{\partial \lambda}=\frac{\left[a-b\left(C_{1}+C_{2}\right)\right]^{2}}{4 b}-\frac{\left[a-b\left(C_{1}+C_{2}\right)\right]^{2}}{8 b}=\frac{R}{(2-\lambda)^{2}}$
$\frac{\left[a-b\left(C_{1}+C_{2}\right)\right]^{2}}{4 b}=R \quad$, critical $\quad$ preference of operator: $\lambda_{1}^{*}=0.586 \quad$ Operator's preference interval is $\lambda_{1} \in[0.586,1]$. Similarly, the profit function for telecom agents, its first derivative $\frac{\partial \pi_{2}}{\partial \lambda}=-\frac{\lambda R}{(2-\lambda)^{3}}$, critical preference point of operator $\lambda_{2}^{*}=0.635$, agent preference interval: $\lambda_{2} \in[0,0.635]$. From the above, we can see that the telecom operators and agents have their own preferences interval. In the process of mutual cooperation, market share fell in the range of preferences, and the bigger the better. Seen from Figure 1, the market share range of telecom operators and agents : $[0.586,1] \cap[0,0.635]=[0.586,0.635],\left[\lambda_{1}^{*}, \lambda_{2}^{*}\right]$

Taking into account the actual situation that sharing ratio is ranked at $5 \%$. Let $\lambda=0.6,1-\lambda=0.4$, telecom operators and agents market share cooperation ratio is about 6:4.

\section{RESEARCH OF MARKET SHARE OF THE TELECOM OPERATORS AND AGENTS}

Telecom channel refers to agents and sales of products and services, which locates between telecom operators and consumers. Through sales of telecommunications products and transfer, telecom channel is able to realize value-added growth. As telecommunications business become more complex, the structure of the telecommunications industry channels is increasingly changing and telecom operators are actively adjust the relationship with the agents. With the changing market environment and the increased competition, the telecom market is gradually changed from a seller's to a buyer's market, so that the form owning operating room supplemented by agents could not adapt to need of market competition and development, so the reform of the marketing of telecom operators and service model is the inevitable choice.

As conflicts are everywhere in the social system, channel conflicts are common phenomenon. Competition in the telecommunications industry has already exceeded the boundaries of a single enterprise and extended to the entire value chain. Marketing channels of the telecommunications industry is gradually formed in the long-term competition, as the core of an integrated system, constituted by a series of complex economic organization structure. In diverse, mixed-level structures, the conflicts among the members are inevitable.

\section{REFERENCES}

[1] Ming Song. Study on Channel Conflict and Control in Telecommunication Industry [D].Beijing: Beijing University of Posts and Telecommunications, 2009.

[2] Stern L.W., EI-Ansary A.I., Coughlan A.T. Marketing Channels[M]. New Jersey: Prentice Hall, Upper Saddle River, 2001. 
[3] Guijun Zhuang. Theories and a model of marketing channel control [J]. Chinese Journal of Management,2004,(1):7-9.

[4] Gilbert A., Bacheldor B. The Big Squeeze[J]. Information Week, 2000, March 27:47-52.

[5] Tsay A.A., Agrawal N. Channel Conflict and Coordination in the Ecommerce Age[J]. Production and Operations Management Society, 2004, Vol.13, No.1:93-110.

[6] Porter M.E. Strategy and the Internet[J]. Harvard Business Review, 2001, Vol.79, No.3:63-78

[7] Kotler P. Marketing Management[M]. London: Prentice Hall Inc, 2000:167-198.

[8] Xianguo Li. Analysis of Causes of Channel Conflicts [J]. Commercial Economics Review,2005,(1):52-56.
[9] Xiujun Zhu, Ze Qi.Conflicts and Cooperation of Marketing Channel in Game Theory [J].Business Economics and administration,2002,(4):14-17.

[10] Ancarani F., Shankar V. Price Levels and Price Dispersion within and Across Multiple Retailer Types: Further Evidence and Extension[J]. Journal of the Academy of Marketing Science, 2004, Vol.32, No.2:176-187.

[11] Chenglin Liao, Zhongwei Liu.Game Analysis of Manufacturers and Distributors of Channel Management [J].Journal of Chongqing University,2003,(2):141-144.

[12] Qi Fan. Conflict Control of the Sales Channels of the Supply Chain from Game Theory[J]. Industrial Technology \& Economy,2008,(9):142-145. 